Article

\title{
Acerogenin A from Acer nikoense Maxim Prevents Oxidative Stress-Induced Neuronal Cell Death through Nrf2-Mediated Heme Oxygenase-1 Expression in Mouse Hippocampal HT22 Cell Line
}

\section{Dong-Sung Lee ${ }^{1}$, Byung-Yoon Cha ${ }^{2}$, Je-Tae Woo ${ }^{2}$, Youn-Chul Kim ${ }^{3}$ and Jun-Hyeog Jang ${ }^{4, *}$}

1 Department of Biomedical Chemistry, College of Health and Biomedical Science, Konkuk University, Chung-Ju 380-701, Korea; E-Mail: dslee@kku.ac.kr

2 Research Institute for Biological Functions, Chubu University, 1200 Matsumoto, Kasugai, Aichi 487-8501, Japan; E-Mails: bycha@isc.chubu.ac.jp (B.-Y.C.); jwoo@isc.chubu.ac.jp (J.-T.W.)

3 College of Pharmacy, Wonkwang University, Iksan 570-749, Korea; E-Mail: yckim@wku.ac.kr

4 Department of Biochemistry, Inha University School of Medicine, Incheon 400-712, Korea

* Author to whom correspondence should be addressed; E-Mail: juhjang@inha.ac.kr; Tel.: +82-32-890-0933; Fax: +82-32-882-1877.

Academic Editor: Peter Koulen

Received: 27 May 2015 / Accepted: 7 July 2015 / Published: 9 July 2015

\begin{abstract}
Oxidative cell damage contributes to neuronal degeneration in many central nervous system (CNS) diseases such as Parkinson's disease, Alzheimer's disease, and ischemia. Inducible heme oxygenase (HO)-1 acts against oxidants that are thought to play a key role in the pathogenesis of neuronal diseases. The stem bark of Acer nikoense Maxim (Aceraceae) is indigenous to Japan; it has been used in folk medicine as a treatment of hepatic disorders and eye diseases. Acerogenin A, a natural compound isolated from Japanese folk medicine A. nikoense, showed neuroprotective effects and reactive oxygen species (ROS) reduction on glutamate-induced neurotoxicity by inducing the expression of HO-1 in mouse hippocampal HT22 cells. Furthermore, acerogenin A caused the nuclear accumulation of nuclear factor-E2-related factor 2 (Nrf2) and the activation of the PI3K/AKT signaling pathways. In this study, we demonstrated that acerogenin A effectively prevents glutamate-induced oxidative damage, and HO-1 induction via PI3K/Akt and Nrf2 pathways appears to play a key role in the protection of HT22 cells. Therefore, this study implies that the Nrf2/HO-1 pathway represents a biological target and that acerogenin A might be a candidate for the prevention of neurodegeneration.
\end{abstract}


Keywords: acerogenin A; mouse hippocampal HT22 cells; neuro-protective effects; heme oxygenase-1; nuclear factor-E2-related factor 2

\section{Introduction}

The initial factors that cause neuronal death remain unclear. Brain tissues are vulnerable to oxidative stress and inflammation that may occur physiologically as a component of aging process or pathologically as a result of neurodegenerative disease [1]. Oxidative stress not only results in accidental damage to cells, but also actively triggers intracellular signaling pathways that lead to cell death [2]. Many neurodegenerative diseases such as ALS, Parkinson's, Alzheimer's, and Huntington's occur as a result of neurodegenerative processes. Neuronal oxidative stress has been postulated as the underlying basis for neuronal cell death in neurodegenerative diseases [3]. To counteract oxidative stress, cells possess a variety of antioxidant systems. There are enzymatic antioxidants, such as glutathione peroxidase, superoxide dismutase, catalase, and phase II detoxifying enzymes, which contribute to xenobiotic detoxification and expression of stress response proteins, such as heme oxygenase-1 (HO-1) [4]. HO-1 is a protein that plays a cytoprotective role against neuronal apoptosis and neuro-inflammation [5]. HO-1 is an enzyme that catalyzes the degradation of the heme group to produces carbon monoxide (CO), biliverdin, and free iron. HO-1 and its enzymatic by-products appear to play important roles in regulating biological responses, including oxidative stress, inflammation, and cell proliferation [6]. The expression of HO-1 also has cytoprotective effects against glutamate-induced oxidative cytotoxicity in HT22 cells [7,8].

The stem bark of Acer nikoense Maxim (Aceraceae) is indigenous to Japan which has been used in folk medicine as a treatment of hepatic disorders and eye diseases [9]. Constituents previously isolated from A. nikoense are diarylheptanoids, phenolic compounds, and tannin, and their bioactivities such as anti-inflammatory effects and protective effects against hepatic injury were also reported [10-12]. Acerogenin A was isolated from A. nikoense. Many products structurally related to acerogenin A have been identified. This compound exerts several biological effects such as the inhibitory effects on degranulation in basophilic leukemia cells [13], the protective effects against hepatic injury [14], and the inhibitory effects on nitric oxide production in lipopolysaccharide-activated macrophages [11], which is a specific activity of acerogenin A. However, there have been no studies on the molecular targets of acerogenin A and the mechanisms underlying their anti-neurodegenerative biological activities. In the present study, we isolated acerogenin A and investigated its neuroprotective effects on glutamate-induced oxidative toxicity in mouse hippocampal HT22 cells through nuclear factor E2-related factor 2 (Nrf2)-dependent HO-1 expression via activation of the phosphatidylinositol 3-kinase (PI3K)/AKT pathways.

\section{Results and Discussion}

\subsection{Effects of Acerogenin A on Glutamate-Induced Cytotoxicity and Inhibition of ROS Generation in HT22 Cells}

Neurodegenerative diseases are incurable, and these results in progressive degeneration or damage of various neuronal cells. Neuronal oxidative stress has been postulated to be the underlying basis for 
neuronal cell death in neurodegenerative diseases [1,2]. Natural products and traditional medicines afford significant promise for the identification of bioactive components and their development into drugs for the treatment of various human disorders, including neuronal diseases. Acerogenin A was isolated from the stem bark of Acer nikoense Maxim, and it has been used in folk medicine as a remedy for hepatic disorders and eyewash. Nagai et al. first isolated acerogenin A from the stem bark of A. nikoense in 1976 [15]. In addition, other studies showed that acerogenin A exert several biological actions $[11,13,14]$, but no study has yet been published on the mechanism studies of neuro-protective active components from A. nikoense or acerogenin A

In this study, we examined the protective effects of acerogenin A against glutamate-induced cytotoxicity in mouse hippocampal HT22 cells. The MTT assay is a widely accepted cytotoxicity assay which can produce inaccurate results due to possible interference with the antioxidant property of phenolic compounds such as acerogenin A [16,17]. Therefore, we have also provided another evidence for the cytotoxic effects of acerogenin A by neutral red assay. To determine the cytotoxic potential of acerogenin A (Figure 1A), its effects on viability of HT22 cells (Figure 1B,C) were evaluated. Concentration of $30 \mu \mathrm{M}$ revealed no cytotoxic effects using the MTT assay (Figure 1B) and neutral red assay (Figure 1C). However, a higher concentration at $40 \mu \mathrm{M}$ showed a slightly reduced viability of these cells (Data not shown). Glutamate toxicity is a major contributor to pathological cell death within the nervous system [18]. Next, we investigated whether acerogenin A affected glutamate-induced oxidative neurotoxicity and ROS generation in HT22 cells. Next, we investigated to determine the protective effects of acerogenin A using the MTT assay (A) and neutral red assay (B). The viability of only glutamate-treated HT22 cells for $12 \mathrm{~h}$ was lower than in the control group, but pre-treatment with acerogenin $\mathrm{A}(5,15$ and $30 \mu \mathrm{M})$ for $6 \mathrm{~h}$ increased viability in a dose-dependent manner (Figure 2A-C). Glutamate also doubled ROS production, and acerogenin A effectively suppressed this induction (Figure 2D). Trolox, a well-known anti-oxidative agent $[19,20]$, was used as positive control, and showed a significantly cytoprotective effect and ROS scavenging activity at a concentration of $50 \mu \mathrm{M}$.

A

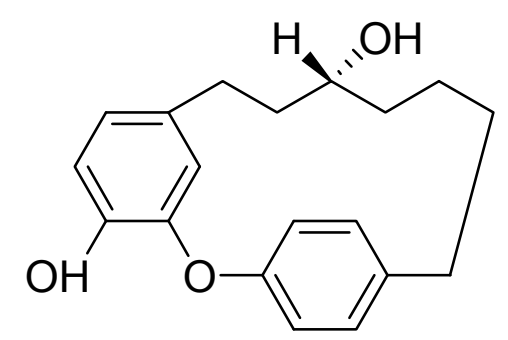

Acerogenin A

Figure 1. Cont. 
B

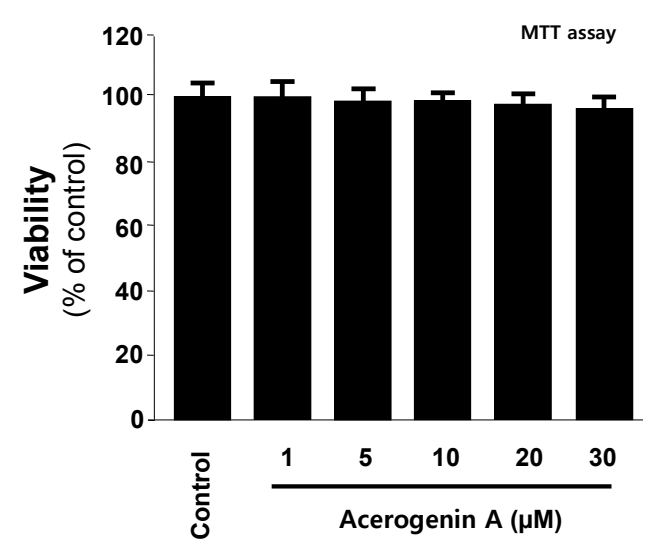

C

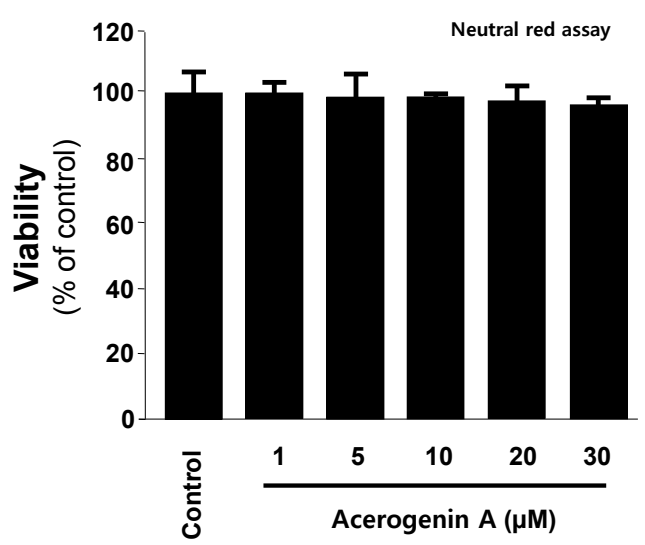

Figure 1. The structure of acerogenin A (A) and the effects of acerogenin A on cell viability by MTT assay $(\mathbf{B})$ and neutral red assay $(\mathbf{C})$. HT22 cells were incubated for $48 \mathrm{~h}$ with various concentrations of acerogenin $\mathrm{A}(1-30 \mu \mathrm{M})(\mathbf{B}, \mathbf{C})$. Data are presented as mean $\pm \mathrm{SD}$ values of three independent experiments.
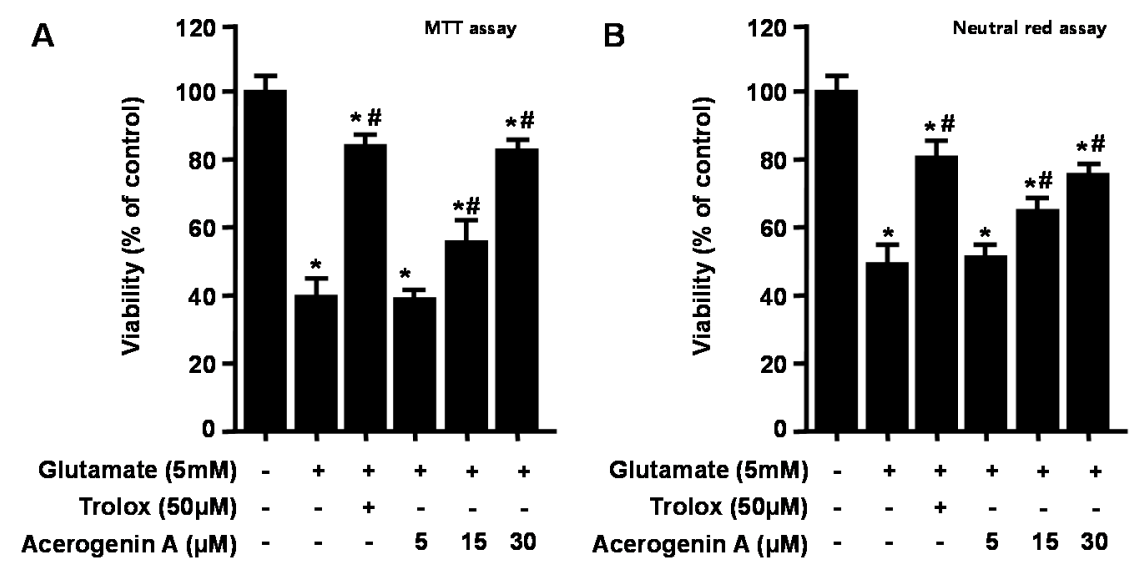

C

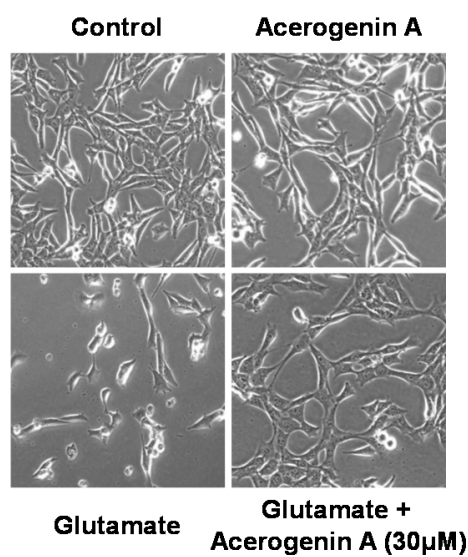

D

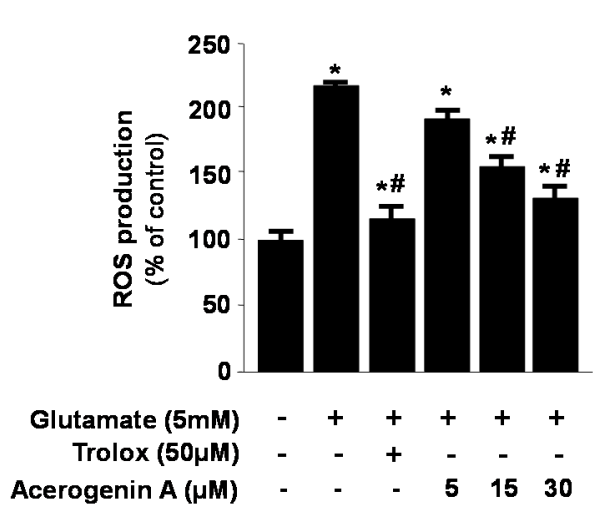

Figure 2. The effects of acerogenin A on glutamate-induced oxidative neurotoxicity (A-C) and inhibition of reactive oxygen species (ROS) generation (D). HT22 cells were pretreated with the indicated concentrations of acerogenin A for $12 \mathrm{~h}$, and then treated with glutamate $(5 \mathrm{mM})$ for $12 \mathrm{~h}(\mathbf{A}-\mathbf{C})$. Exposure of HT22 cells to glutamate increased ROS production (D). Data are presented as mean \pm SD values of three independent experiments. Trolox $(50 \mu \mathrm{M})$ was used as the positive control. ${ }^{*} p<0.05$ vs. control. ${ }^{\#} p<0.05$ vs. glutamate. 


\subsection{Effects of Acerogenin A on Glutamate-Induced Oxidative Neurotoxicity through HO-1 Expression} Pathway in HT22 Cells

In our previous studies, we have demonstrated that HO-1 expression appeared to play key roles in cytoprotection in HT22 cells [19,20]. In addition, HO-1 and the subsequent metabolites of heme catabolism appear to play vital roles in regulating important biological responses including inflammation, oxidative stress, cell survival, and cell proliferation $[21,22]$. Therefore, we have provided evidence for the induction of HO-1 expression by acerogenin A in HT22 cells. At non-cytotoxic concentrations (15 and $30 \mu \mathrm{M})$, we examined whether acerogenin A affected HO-1 protein immunocontents by treating the HT22 cells with this agent for $12 \mathrm{~h}$. Acerogenin A increased HO-1 mRNA expression in HT22 cells (Figure 3A). In addition, acerogenin A also dose-dependently increased HO-1 protein expression in HT22 cells (Figure 3B). CoPP $(20 \mu \mathrm{M})$, a well-known HO-1 inducer, was used as the positive control [19,20]. To confirm that pre-incubation with acerogenin A markedly showed cytoprotective effect and ROS scavenging activity (Figure 1) and this effect was correlated with acerogenin A-mediated HO-1 expression (Figure 3), we investigated whether the effect of acerogenin A-mediated HO-1 expression was reversed by pre-treatment with SnPP, an inhibitor of HO-1 (Figure 3C,D) [19,20]. HT22 cells were co-treated with acerogenin A for $12 \mathrm{~h}$ in the absence or presence of SnPP, which is an inhibitor of HO-1 activity. SnPP significantly inhibited the acerogenin A-mediated cytoprotection using the MTT assay (Figure 3C). The acerogenin A-induced HO-1 expression was also required for suppressing glutamate-induced ROS generation (Figure 3D). In addition, the role of HO-1 expression by acerogenin A on the cytoprotective effect and ROS scavenging activity were studied using siRNA against HO-1. HT22 cells were transiently transfected with siRNA HO-1, and then were treated with acerogenin A followed by glutamate stimulation. As shown in Figure 3, SnPP treatment and transient transfection with HO-1 siRNA partially reversed the cytoprotective effect and ROS scavenging activity of acerogenin A. The results supported the hypothesis that induction of HO-1 contributes to the cytoprotective effects of acerogenin A on the HT22 cells.

A

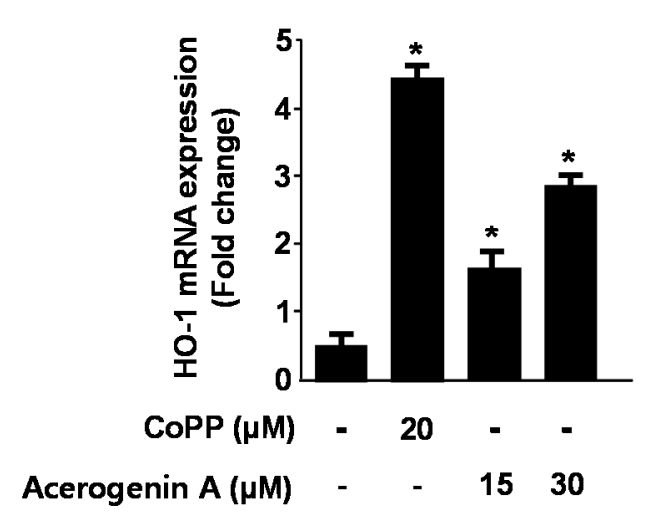

B

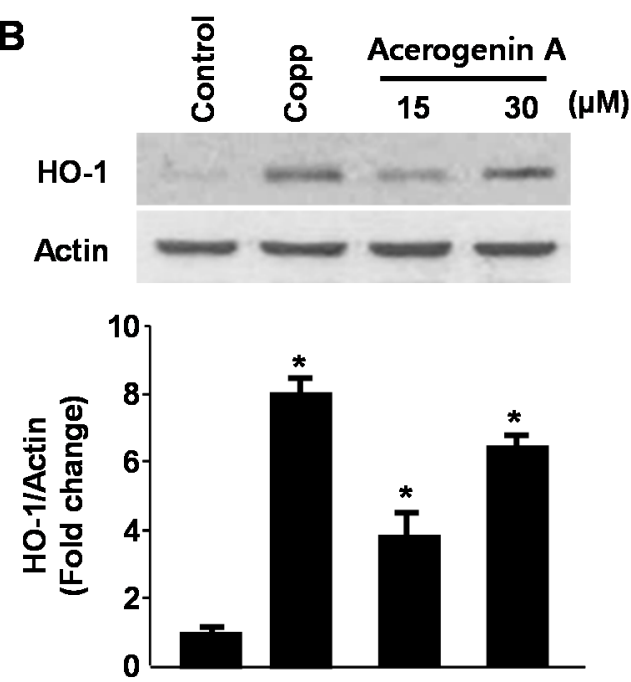

Figure 3. Cont. 

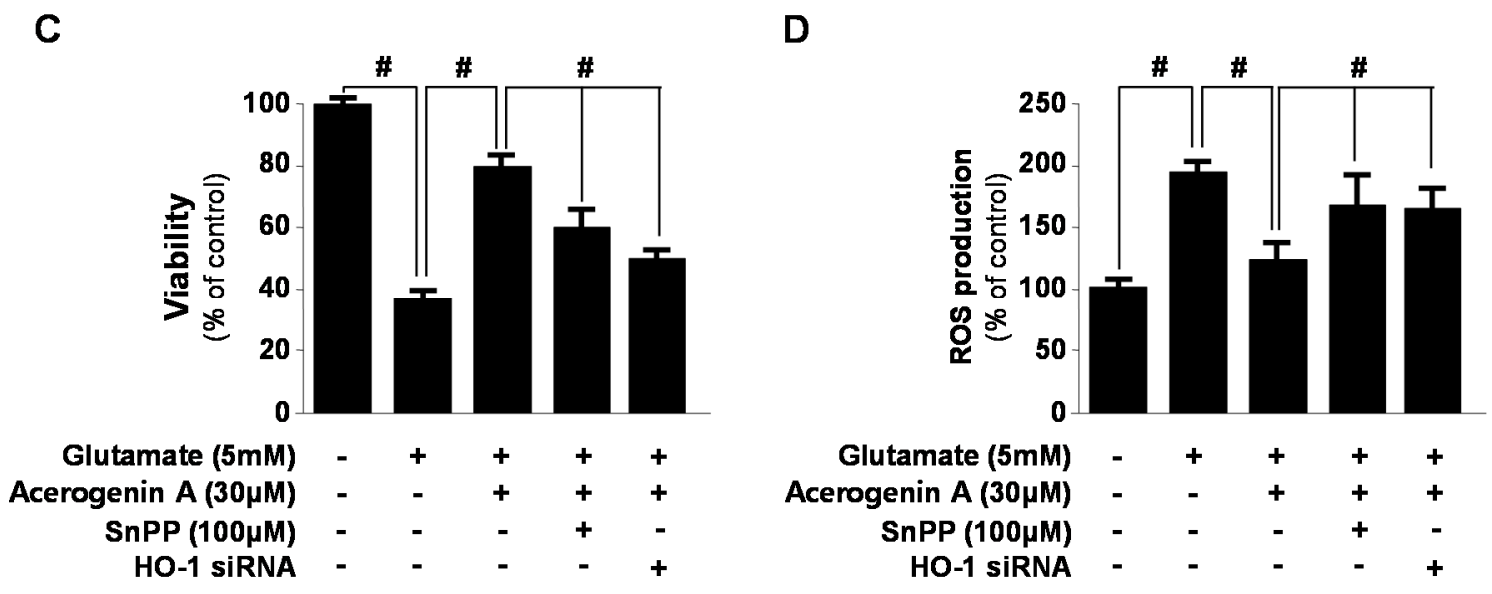

Figure 3. The effects of acerogenin $A$ on heme oxygenase (HO)-1 expression $(\mathbf{A}, \mathbf{B})$ and acerogenin A-induced HO-1 on glutamate-induced oxidative neurotoxicity $(\mathbf{C})$ and ROS generation (D). HT22 cells were incubated with indicated concentrations of acerogenin A for $12 \mathrm{~h}(\mathbf{A}, \mathbf{B})$. HT22 cells were treated with $30 \mu \mathrm{M}$ of acerogenin A in the presence or absence of $50 \mu \mathrm{M}$ SnPP IX and HO-1 siRNA, and then exposed to glutamate $(5 \mathrm{mM})$ for $12 \mathrm{~h}(\mathbf{C}, \mathbf{D})$. Exposure of HT2 2 cells to $5 \mathrm{mM}$ glutamate for $12 \mathrm{~h}$ to increase ROS production, followed by incubation with $10 \mu \mathrm{M}$ of the ROS-sensitive fluorophore dichlorofluorescein (DCF) (D). Western blot analysis was performed, and representative blots of three independent experiments are shown. Data are presented as the mean \pm SD values of three independent experiments. ${ }^{*} p<0.05$ vs. control. ${ }^{*} p<0.05$.

\subsection{Effects of Acerogenin A on Nrf2 Nuclear Translocation and Nrf2-Mediated HO-1 Expression in HT22 Cells}

Numerous transcription factors participate in the regulation of HO-1 expression, with tendencies for one or more signaling pathways to predominate in a species-specific manner. Nrf2 is a basic leucine zipper transcription factor that resides in the cytoplasm bound to its inhibitor protein, Keap 1, and translocates to the nucleus after stimulation. It then binds to the ARE sequences in the promoter regions of specific genes [23]. Nrf2 has been known to induce the expression of antioxidant stress proteins such as HO-1 and glutathione (GSH) [24]. Therefore, we investigated whether treatment with acerogenin A induces the translocation of Nrf2 to the nuclei in HT22 cells. Cells were treated with acerogenin A for 30, 60, and $120 \mathrm{~min}$, and the level of Nrf2 protein was then determined by western blotting. Western blot analysis of the nuclear fraction of acerogenin A-treated HT22 cells showed a gradual increase in Nrf2 levels, whereas a concomitant decrease was observed in the cytoplasmic fractions (Figure 4A). Furthermore, the role of Nrf2 in HO-1 expression by acerogenin A was studied using siRNA against Nrf2. HT22 cells were transiently transfected with siRNA Nrf2 and then were treated with acerogenin A for $12 \mathrm{~h}$ to induce HO-1 expression. As shown in Figure 4B, Nrf2 siRNA have completely blocked off nuclear translocation of Nrf2. In addition, transient transfection with Nrf2 siRNA also abolishes induction of HO-1 expression by acerogenin A in both HT22 cells. These results indicated that HO-1 induction upon incubation with acerogenin A is related to the Nrf nuclear translocation pathway in HT22 cells. 


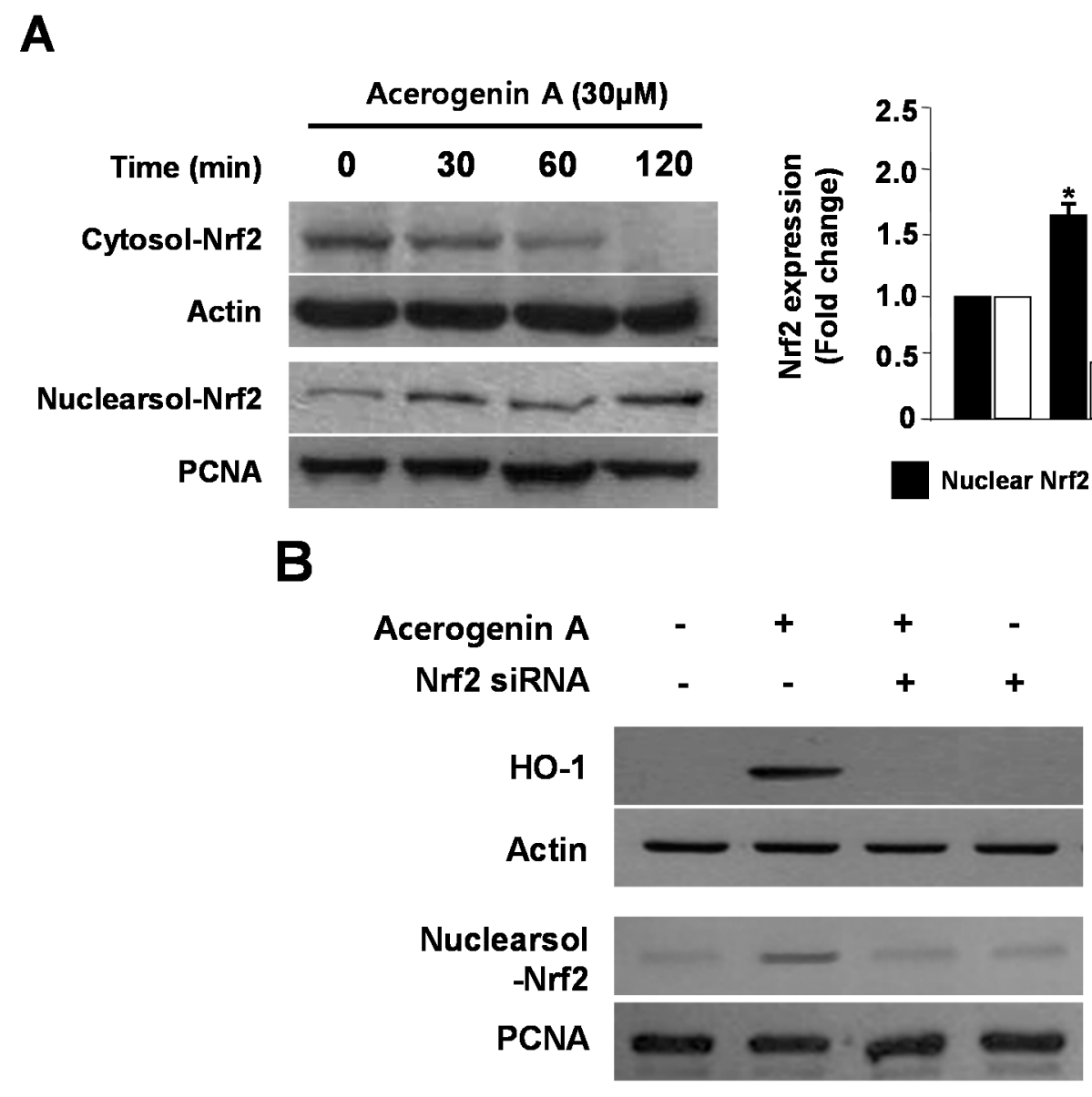

Figure 4. The effects of acerogenin $A$ on the nuclear translocation of $\mathrm{Nrf2}$ (A) and Nrf2-mediated HO-1 (B) in HT22 cells. HT22 cells were treated with $30 \mu \mathrm{M}$ of acerogenin A for $0,30,60$, and $90 \mathrm{~min}$ (A). The nuclei were fractionated from the cytosol by using PER-Mammalian Protein Extraction Buffer, as described in the Experimental Section (A). HT22 cells were transiently transfected with Nrf2 siRNA and then treated with $30 \mu \mathrm{M}$ acerogenin A for $12 \mathrm{~h}(\mathbf{B})$. Western blot analysis was performed, and representative blots of three independent experiments are shown. Data are presented as the mean value \pm SD values of three independent experiments. $* p<0.05 v s$. control.

\subsection{Involvement of the PI3K/Akt Pathway in Acerogenin A-Induced HO-1 Expression}

In previous studies, phosphatidylinositol 3-kinase (PI3K) was demonstrated to be involved in HO-1 induction by various phytochemicals [25]. Upstream signaling pathways were also implicated in the regulation of HO-1 expression, such as PI3K/AKT pathway [26]. Therefore, we tested whether acerogenin A-induced expression of HO-1 occurs through the PI3K pathway. To correlate the activation of Akt with the induction of HO-1 by acerogenin A, we investigated Akt phosphorylation by acerogenin A in HT22 cells by using an anti-phospho-Akt antibody. Akt was phosphorylated from 0 to 60 min by acerogenin A (Figure 5A), and its phosphorylation slowly declined thereafter in HT22 cells (Data not shown). Moreover, the PI3K pathway inhibitor (LY294002) abolishes acerogenin A-induced HO-1 expression (Figure 5B) and cytoprotection (Figure 5C) in HT22 cells. Therefore, we suggest that Nrf2-mediated HO-1 induction by acerogenin A is related to the PI3K/Akt pathway in HT22 cells. 
A
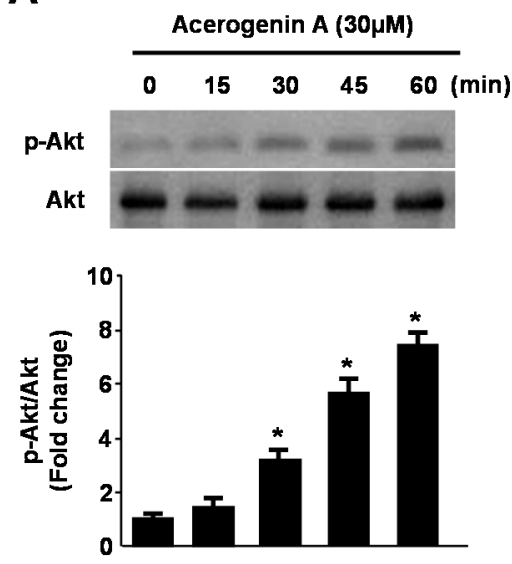

B

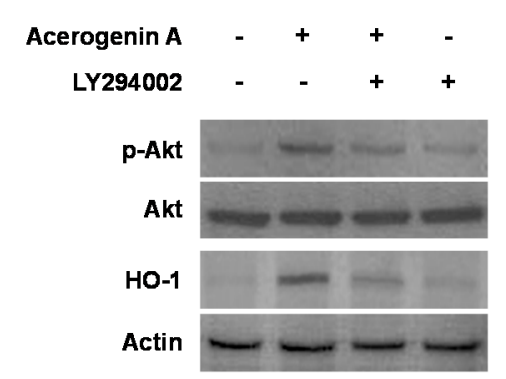

C

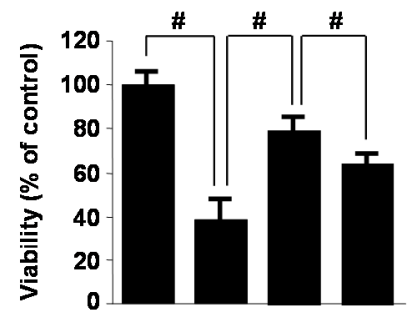

$\begin{array}{rllll}\text { Glutamate }(5 \mathrm{mM}) & - & + & + & + \\ \text { Acerogenin A }(30 \mu M) & - & - & + & + \\ \text { LY294002 } & - & - & - & +\end{array}$

Figure 5. Effects of acerogenin A-induced HO-1 expression through the phosphatidylinositol 3-kinase (PI3K)/AKT cascade. HT22 cells were treated with acerogenin A $(30 \mu \mathrm{M})$ for the indicated times (A). HT22 cells were pre-incubated with or without $10 \mu \mathrm{M} \mathrm{LY} 294002$ for $1 \mathrm{~h}$ and then incubated in the absence or presence of $20 \mu \mathrm{M}$ of acerogenin A for $60 \mathrm{~min}$ (p-AKT) or $12 \mathrm{~h}(\mathrm{HO}-1)(\mathbf{B})$. HT2 2 cells untreated or treated with acerogenin A $(30 \mu \mathrm{M})$ in the presence or absence of LY294002 $(10 \mu \mathrm{M})$ for $12 \mathrm{~h}$ were exposed to $5 \mathrm{mM}$ glutamate for $12 \mathrm{~h}(\mathbf{C})$. Western blot analysis was performed, and representative blots of three independent experiments are shown. Data are presented as the mean \pm SD values of three independent experiments. ${ }^{*} p<0.05$ vs. control. ${ }^{*} p<0.05$.

\section{Experimental Section}

\subsection{Chemicals and Reagents}

Dulbecco's modified Eagle's medium (DMEM), fetal bovine serum (FBS), and other tissue culture reagents were purchased from Gibco BRL Co (Carlsbad, CA, USA). Cobalt protoporphyrin (CoPP), an inducer of HO-1, and tin protoporphyrin IX (SnPP IX), an inhibitor of HO activity, were obtained from Porphyrin Products. Lipofectamine 2000TM was purchased from Invitrogen Life Technologies (Grand Island, NY, USA). Small interfering RNA (siRNA) for HO-1 and Nrf2, and all other chemicals were obtained from Sigma Chemical Co. (St. Louis, MO, USA) unless otherwise stated. Primary antibodies, including mouse/goat/rabbit anti-HO-1, Nrf-2, p-Akt, Akt, and Actin, and secondary antibodies were purchased from Santa Cruz Biotechnology (Santa Cruz, CA, USA). Acerogein A was provided from Prof. Byung-Yoon Cha.

\subsection{Cell Culture}

Mouse hippocampal HT22 cells were received from Dr. Inhee-Mook (Seoul National University, Seoul, Korea). The cells were maintained at $5 \times 10^{6}$ cells/dish in 100-mm dishes in DMEM supplemented with 10\% heat-inactivated FBS, penicillin G (100 units $/ \mathrm{mL})$, streptomycin (100 $\mu \mathrm{g} / \mathrm{mL})$, and L-glutamine $\left(2 \mathrm{mM}\right.$ ), and incubated at $37{ }^{\circ} \mathrm{C}$ in a humidified atmosphere containing $5 \% \mathrm{CO}_{2}$ and $95 \%$ air. For determination of cell viability, cells $\left(2 \times 10^{4}\right.$ cells/well in 96-well plates) were incubated with 3-(4,5dimethylthiazol-2-yl)-2,5-diphenyltetrazolium bromide (MTT) at a final concentration of $0.5 \mathrm{mg} / \mathrm{mL}$ for 
$4 \mathrm{~h}$, and the formazan formed was dissolved in acidic 2-propanol. Optical density was measured at $590 \mathrm{~nm}$ with a microplate reader (Bio-Rad, Hercules, CA, USA). The optical density of the formazan formed in control (untreated) cells was considered to represent $100 \%$ viability.

\subsection{MTT Assay and Neutral Red Assay}

For determination of cell viability by MTT assay, HT22 cells $\left(2 \times 10^{4}\right.$ cells/well in 96-well plates $)$ were treated with acerogenin $\mathrm{A}$ in the presence or absence of $5 \mathrm{mM}$ glutamate and incubated for indicated times. Next, the cell culture media from each well was removed, and the wells were rinsed multiple times with DPBS. After then, each wells replaced with $200 \mu \mathrm{L}$ of fresh media. Next, cells were incubated with 3-(4,5-dimethylthiazol-2-yl)-2,5-diphenyltetrazolium bromide (MTT) at a final concentration of $0.5 \mathrm{mg} / \mathrm{mL}$ for $4 \mathrm{~h}$, and the formazan formed was dissolved in acidic 2-propanol. Optical density was measured at $590 \mathrm{~nm}$ with a microplate reader (Bio-Rad, Hercules, CA, USA). The optical density of the formazan formed in control (untreated) cells was considered to represent $100 \%$ viability. In addition, cell viability in terms of lysosomal integrity was measured by neutral red assay (Sigma-Aldrich, New York, NY, USA). HT2 2 cells $\left(2 \times 10^{4}\right.$ cells/well in 96-well plates $)$ were treated with acerogenin A. Next, the cell culture media from each well was removed, and washed twice with PBS. After each time point, the media was removed, and the wells were rinsed multiple times with DPBS. After the DPBS washes, $200 \mu \mathrm{L}$ of fresh media was added to each well along with $10 \mu \mathrm{L}$ of neutral red reagent $(0.33 \%$ in DPBS), followed by incubation for $4 \mathrm{~h}$ at $37^{\circ} \mathrm{C}$. The neutral red reagent was removed, and cells were treated with $100 \mu \mathrm{L}$ of neutral red assay fixative for $1 \mathrm{~min}$ followed by $100 \mu \mathrm{L}$ of neutral red assay solubilization reagent. Absorbance of culture media at $490 \mathrm{~nm}$ was used for microplate reader (Bio-Rad, Hercules, CA, USA). The optical density formed in control (untreated) cells was considered to represent $100 \%$ viability.

\subsection{ROS Measurement}

For measurement of ROS, HT22 cells $\left(2.5 \times 10^{4}\right.$ cells/well in 24-well plates) were treated with $5 \mathrm{mM}$ glutamate in the presence or absence of acerogenin A or SnPP IX (HO inhibitor) and incubated for $8 \mathrm{~h}$. After washing with phosphate-buffered saline (PBS), the cells were stained with $10 \mu \mathrm{M}$ $2^{\prime}, 7^{\prime}$-dichlorofluorescein diacetate (DCFDA) in Hank's balanced salt solution for $30 \mathrm{~min}$ in the dark. The cells were then washed twice with PBS and extracted with 1\% Triton X-100 in PBS for 10 min at $37{ }^{\circ} \mathrm{C}$. Fluorescence was recorded at an excitation wavelength of $490 \mathrm{~nm}$ and an emission wavelength of $525 \mathrm{~nm}$ (Spectramax Gemini XS; Molecular Devices, Sunnyvale, CA, USA). Cells were immediately observed under a laser-scanning confocal microscope (Leica TCS SP2). DCF fluorescence was excited at $488 \mathrm{~nm}$ with an argon laser, and the evoked emission was filtered with a 515-nm long pass filter.

\subsection{Preparation of Nuclear and Cytosolic Fractions}

Cells were homogenized (1:20,w/v) in PER-Mammalian Protein Extraction buffer (Pierce Biotechnology, Rockford, IL, USA) containing freshly added protease inhibitor cocktail I (EMD Biosciences, San Diego, CA, USA) and $1 \mathrm{mM}$ phenylmethylsulfonyl fluoride. The cytosolic fraction of cells was prepared by centrifugation at $15,000 \times g$ for $10 \mathrm{~min}$ at $4{ }^{\circ} \mathrm{C}$. Nuclear and cytoplasmic extracts of HT22 cells were prepared using NE-PER nuclear and cytoplasmic extraction reagents (Pierce Biotechnology, Rockford, 
IL, USA), respectively. After treatment, HT22 cells $\left(3 \times 10^{6}\right.$ cells $/ 3 \mathrm{~mL}$ in a $60-\mathrm{mm}$ dish) were collected and washed with PBS. After centrifugation at $1000 \mathrm{rpm}$ for $3 \mathrm{~min}$, cell lysis was performed at $4{ }^{\circ} \mathrm{C}$ by vigorous shaking for $15 \mathrm{~min}$ in RIPA buffer ( $150 \mathrm{mM} \mathrm{NaCl}, 1 \% \mathrm{NP}-40,0.5 \%$ sodium deoxycholate, $0.1 \%$ sodium dodecyl sulfate, $50 \mathrm{mM}$ Tris- $\mathrm{HCl}(\mathrm{pH} 7.4), 50 \mathrm{mM}$ glycerophosphate, $20 \mathrm{mM} \mathrm{NaF}, 20 \mathrm{mM}$ ethylene glycol tetraacetic acid, $1 \mathrm{mM}$ dithiothreitol, $1 \mathrm{mM} \mathrm{Na} 3 \mathrm{VO}_{4}$, and protease inhibitors). After centrifugation at $14,800 \times \mathrm{g}$ for $15 \mathrm{~min}$, the supernatant was separated and stored at $-70{ }^{\circ} \mathrm{C}$ until further use. The protein content was determined using a bicinchoninic acid protein assay kit.

\subsection{Western Blot Analysis}

Cells were harvested and pelleted by centrifugation at $200 \times g$ for $3 \mathrm{~min}$. Subsequently, the cells were washed with PBS and lysed in $20 \mathrm{mM}$ Tris- $\mathrm{HCl}$ buffer $(\mathrm{pH} 7.4)$ containing a protease inhibitor mixture (0.1 mM phenylmethylsulfonyl fluoride, $5 \mathrm{mg} / \mathrm{mL}$ aprotinin, $5 \mathrm{mg} / \mathrm{mL}$ pepstatin $\mathrm{A}$, and $1 \mathrm{mg} / \mathrm{mL}$ chymostatin). The protein concentration was determined using the Lowry Protein Assay Kit (P5626; Sigma Chemical Co.). An equal amount of protein from each sample was resolved using 12\% sodium dodecyl sulfate-polyacrylamide gel electrophoresis and then electrophoretically transferred onto a Hybond-enhanced chemiluminescence nitrocellulose membrane (Bio-Rad). The membrane was blocked with 5\% skimmed milk and incubated with anti-HO-1, anti-Nrf2, anti-Akt, anti-phospho-Akt, or anti-actin antibodies (all of which were used at a 1:1000 dilution and purchased from Santa Cruz Biotechnology) at $4{ }^{\circ} \mathrm{C}$ overnight. The immunoreactive bands were visualized using a horseradish peroxidase-conjugated secondary antibody (1:1000 dilution; Santa Cruz Biotechnology) followed by enhanced chemiluminescence detection (Amersham Pharmacia Biotech, Piscataway, NJ, USA) and quantified using an image analysis program (Image Gauge v3.12 software; Fujifilm, Tokyo, Japan).

\subsection{Transfection}

Cells were transiently transfected with HO-1 siRNA and Nrf2 siRNA for 6 h by using Lipofectamine $2000^{\mathrm{TM}}$ (Invitrogen, Carlsbad, CA, USA) according to the manufacturer's protocol, and recovered in fresh media containing $10 \%$ FBS for $24 \mathrm{~h}$.

\subsection{RNA Quantification}

Total RNA was extracted from harvested cells for reverse transcription polymerase chain reaction (RT-PCR) using the TRIzol System (Invitrogen). The RNA isolation protocol included a DNase I treatment. We quantified RNA and reverse transcribed cDNAs from $1 \mu \mathrm{g}$ of total RNA per $20 \mu \mathrm{L}$ RT reaction with Oligo (dT) 12-8 primers and the SuperScript First-Strand Synthesis System for RT-PCR (Invitrogen, Carlsbad, CA, USA). RT-PCR was conducted in a $25 \mu \mathrm{L}$ solution containing $67.7 \mathrm{mM}$ Tris- $\mathrm{HCl}$ (pH 8.8); $16.6 \mathrm{mM}\left(\mathrm{NH}_{4}\right)_{2} \mathrm{SO}_{4} ; 0.01 \%$ Tween-20; $200 \mathrm{nM}$ each of dATP, dCTP, and dGTP; $400 \mathrm{nM}$ dUTP; $4.5 \mathrm{mM} \mathrm{MgCl}$; $300 \mathrm{nM}$ of each primer; $200 \mathrm{nM}$ probe; $2 \mathrm{U}$ Taq DNA polymerase and 1/10 (by volume) of the cDNA synthesis reaction. Thermal cycling conditions consisted of 4 min at $95{ }^{\circ} \mathrm{C}$ followed by 25 cycles of $15 \mathrm{~s}$ at $95^{\circ} \mathrm{C}$ and $1 \mathrm{~min}$ at $60^{\circ} \mathrm{C}$. The primer sequences were as follows: HO-1, forward 5'-CTCTTGGCTGGCTTCCTT-3', reverse 5'-GGCTCCTTCCTCCTTTCC-3', and glyceraldehyde 
3-phosphate dehydrogenase (GAPDH), forward 5'-ACTTTGGTATCGTGGAAGGACT-3', reverse 5'-GTAGAGGCAGGGATGATGTTCT-3'.

\subsection{Statistical Analysis}

Data were expressed as the mean $\pm \mathrm{SD}$ of at least three independent experiments. To compare three or more groups, one-way analysis of variance (ANOVA) was used followed by Newman-Keuls post hoc test. Statistical analysis was performed using GraphPad Prism software version 3.03 (GraphPad Software Inc., San Diego, CA, USA).

\section{Conclusions}

In conclusion, we demonstrated that acerogenin A effectively prevents glutamate-induced oxidative damage, and HO-1 induction via PI3K/Akt and Nrf2 pathways appears to play a key role in the protection of HT22 cells. This study provides evidence that acerogenin A can exert a neuroprotective effect via activation of the Nrf2-mediated HO-1 expression. To our knowledge, the present study is the first to show that natural compound, acerogenin A, activates Nrf2-mediated HO-1 signaling in HT22 cells and exerts an anti-oxidative defense mechanism against glutamate-induced neurotoxicity. Therefore, this study implies that the Nrf2/HO-1 pathway represents a biological target and that acerogenin A might be a candidate for the prevention of neurodegeneration.

\section{Acknowledgments}

This research was supported by the Basic Science Research Program through the National Research Foundation of Korea (NRF) funded by the Ministry of Education, Science and Technology (MEST) (No. 2012R1A1A2042984), and Inha University Grant.

\section{Author Contributions}

D.-S.L. performed the experiments related to biological evaluation of the compound and wrote the manuscript; B.-Y.C. and J.-T.W. contributed to the isolation of the compound; Y.-C.K. contributed to writing the manuscript; J.-H.J. organized this work and to writing the manuscript.

\section{Conflicts of Interest}

The authors declare no conflict of interest.

\section{References}

1. Hald, A.; Lotharius, J. Oxidative stress and inflammation in Parkinson's disease: Is there a causal link? Exp. Neurol. 2005, 193, 279-290.

2. Keller, J.N.; Mattson, M.P. Roles of lipid peroxidation in modulation of cellular signaling pathways, cell dysfunction, and death in the nervous system. Rev. Neurosci. 1998, 9, 105-116.

3. Simonian, N.A.; Coyle, J.T. Oxidative stress in neurodegenerative diseases. Annu. Rev. Pharmacol. Toxicol. 1996, 36, 83-106. 
4. Boutten, A.; Goven, D.; Boczkowski, J.; Bonay, M. Oxidative stress targets in pulmonary emphysema: Focus on the NRF2 pathway. Expert Opin. Ther. Targets 2010, 14, 329-346.

5. Yoshida, T.; Tuder, R.M. Pathobiology of cigarette smoke induced chronic obstructive pulmonary disease. Physiol. Rev. 2007, 87, 1047-1082.

6. Ryter, S.W.; Otterbein, L.E.; Morse, D.; Choi, A.M.K. Heme oxygenase/carbon monoxide signaling pathways: Regulation and functional significance. Mol. Cell. Biochem. 2002, 37, 249-263.

7. Rőssler, O.G.; Bauer, I.; Chung, H.Y.; Thiel, G. Glutamate-induced cell death of immortalized murine hippocampal neurons: Neuroprotective activity of heme oxygenase-1, heat shock protein 70, and sodium selenite. Neurosci. Lett. 2004, 362, 253-257.

8. Li, B.; Lee, D.S.; Jeong, G.S.; Kim, Y.C. Involvement of heme oxygenase-1 induction in the cytoprotective and immunomodulatory activities of 6,4'-dihydroxy-7-methoxyflavanone in murine hippocampal and microglia cells. Eur. J. Pharmacol. 2012, 674, 153-162.

9. Nagai, M.; Kubo, M.; Fujita, M.; Inoue, T.; Matsuo, M. Studies on the constituents of Aceraceae Plants. II. Structure of aceroside I, a glucose of a novel cyclic diarylheptanoids from Acer nikoense Maxim. Chem. Pharm. Bull. (Tokyo) 1978, 26, 2805-2810.

10. Inoue, T. Constituents of Acer nikoense and Myrica rubra. On diarylheptanoids. Yakugaku Zasshi 1993, 113, 181-197.

11. Morikawa, T.; Tao, J.; Toguchida, I.; Matsuda, H.; Yoshikawa, M. Structures of new cyclic diarylheptanoids and inhibitors of nitric oxide production from Japanese folk medicine Acer nikoense. J. Nat. Prod. 2003, 66, 86-91.

12. Iizuka, T.; Nagumo, S.; Yotsumoto, H.; Moriyama, H.; Nagai, M. Vasorelaxant effects of Acer nikoense extract and isolated coumarinolignans on rat aortic rings. Biol. Pharm. Bull. 2007, 30, 1164-1166.

13. Morikawa, T.; Tao, J.; Ueda, K.; Matsuda, H.; Yoshikawa, M. Medicinal foodstuffs. XXXI. Structures of new aromatic constituents and inhibitors of degranulation in RBL-2H3 cells from Japanese folk medicine, the stem bark of Acer nikoense. Chem. Pharm. Bull. (Tokyo) 2003, 51, $62-67$.

14. Shinoda, M.; Ohta, S.; Kumasaka, M.; Fujita, M.; Nagai, M.; Inoue, T. Protective effect of the bark of Acer nikoense on hepatic injury induced by carbon. Shoyakugaku Zasshi 1986, 40, 177-181.

15. Nagai, M.; Kubo, M.; Fujita, M.; Inoue, T.; Matsuo, M. Acerogenin A, a novel cyclic diarylheptanoid. J. Chem. Soc. Chem. Commun. 1976, 338-339, doi:10.1039/C39760000338.

16. Maioli, E.; Torricelli, C.; Fortino, V.; Carlucci, F.; Tommassini, V.; Pacini, A. Evaluation of viability assays for anthocyanins in cultured cells. Phytochem. Anal. 2008, 19, 479-486.

17. Elisia, I.; Popovich, D.G.; Hu, C.; Kitts, D.D. Accurate assessment of the bioactivities of redox-active polyphenolics in cell culture. J. Agric. Food Chem. 2008, 56, 7831-7837.

18. Mattson, M.P. Apoptosis in neurodegenerative disorders. Nat. Rev. Mol. Cell Biol. 2000, 1, $120-129$.

19. Lee, D.S.; Jeong, G.S. Arylbenzofuran isolated from Dalbergia odorifera suppresses lipopolysaccharide-induced mouse BV2 microglial cell activation, which protects mouse hippocampal HT22 cells death from neuroinflammation-mediated toxicity. Eur. J. Pharmacol. 2014, 728, 1-8.

20. Lee, D.S.; Ko, W.; Kim, D.C.; Kim, Y.C.; Jeong, G.S. Cudarflavone B provides neuroprotection against glutamate-induced mouse hippocampal HT22 cell damage through the Nrf2 and PI3K/Akt signaling pathways. Molecules 2014, 19, 10818-10831. 
21. Lee, D.S.; Jang, J.H.; Ko, W.; Kim, K.S.; Sohn, J.H.; Kang, M.S.; Ahn, J.S.; Kim, Y.C.; Oh, H. PTP1B inhibitory and anti-inflammatory effects of secondary metabolites isolated from the marine-derived fungus Penicillium sp. JF-55. Mar. Drugs 2013, 11, 1409-1426.

22. Lee, D.S.; Li, B.; Kim, K.S.; Jeong, G.S.; Kim, E.C.; Kim, Y.C. Butein protects human dental pulp cells from hydrogen peroxide-induced oxidative toxicity via Nrf2 pathway-dependent heme oxygenase-1 expressions. Toxicol. In Vitro 2013, 27, 874-881.

23. Qiang, W.; Cahill, J.M.; Liu, J.; Kuang, X.; Liu, N.; Scofield, V.L.; Voorhees, J.R.; Reid, A.J.; Yan, M.; Lynn, W.S.; et al. Activation of transcription factor Nrf-2 and its downstream targets in response to moloney murine leukemia virus ts1-induced thiol depletion and oxidative stress in astrocytes. J. Virol. 2004, 78, 11926-11938.

24. Ishii, T.; Itoh, K.; Takahashi, S.; Sato, H.; Yanagawa, T.; Katoh, Y.; Bnnai, S.; Yamamoto, M. Transcription factor Nrf2 coordinately regulates a group of oxidative stress-inducible genes in macrophages. J. Biol. Chem. 2000, 275, 16023-16029.

25. Martin, D.; Rojo, A.I.; Salinas, M.; Diaz, R.; Gallardo, G.; Alam, J.; de Galarreta, C.M.; Cuadrado, A. Regulation of heme oxygenase-1 expression through the phosphatidylinositol 3 '-kinase/Akt pathway and the Nrf2 transcription factor in response to the antioxidant phytochemical carnosol. J. Biol. Chem. 2004, 279, 8919-8929.

26. Wu, C.C.; Hsu, M.C.; Hsieh, C.W.; Lin, J.B.; Lai, P.H.; Wung, B.S. Upregulation of heme oxygenase-1 by Epigallocatechin-3-gallate via the phosphatidylinositol 3-kinase/Akt and ERK pathways. Life Sci. 2006, 78, 2889-2897.

Sample Availability: Samples of the acerogenin A are available from the authors.

(C) 2015 by the authors; licensee MDPI, Basel, Switzerland. This article is an open access article distributed under the terms and conditions of the Creative Commons Attribution license (http://creativecommons.org/licenses/by/4.0/). 